\title{
Evaluating the Growth Performance of Two Azotobactor spp. in Liquid Glucose Broth and Tryptic Peptone Broth as Inoculum for the Production of Bio-Fertilizers
}

\author{
A. D. Nagalla, D.V. Jayatilake, V. Herath ${ }^{1^{*}}$ and L.D.B. Suriyagoda ${ }^{2}$ \\ Postgraduate Institution of Agriculture \\ University of Peradeniya \\ Sri Lanka
}

\begin{abstract}
Biofertilizers with Azotobacter spp. releases available nitrogen to the plant rhizosphere. A media that yield a high viable inoculum cell count in a shorter incubation period is important for commercial production of biofertilizers. Current study evaluates the growth performances of Azotobacter chroococcum and Azotobacter vinelandii, two spp. commonly found in sugarcane rhizosphere, in two broth cultures: tryptic peptone broth (TPB) and liquid glucose broth (LGB) using optical density (OD) measurements at a wavelength of $620 \mathrm{~nm}$ over an incubation period of $12-15$ hours. The analysis of variance revealed significant $(p<0.001)$ species, broth and species $\times$ broth interaction on OD. Azotobacter spp. had a higher growth rate in the protein enriched $T P B$ compared to LGB. Azotobacter chroococcum had a higher growth rate than $\underline{A}$. vinelandii particularly in TPB. Despite the cost, $A$. chroococcum inoculum grown in TPB can be recommended for commercial biofertilizer production, due to yield and time advantage.
\end{abstract}

Keywords: Azotobacter, Bio-fertilizers, Inoculation media, Liquid glucose broth, Tryptic peptone broth

\section{INTRODUCTION}

Bio-fertilizers are looked upon as an eco-friendly and sustainable mode of supplementing the soil with nutrients compared to the use of synthetic fertilizers (Singh et al., 2011). Previous studies have shown that nitrogen fixing bacteria such as Azospirillum spp. (Yasari \& Patwardhan, 2007) and Azotobacter spp. (Kizilkaya, 2008) can potentially be used in bio-fertilizers to enhance crop production.

Azotobacter is a soil borne, free-living nitrogen fixing bacterial genus, abundantly found in sugarcane plantations (Tejera et al., 2005). The spent-wash from sugarcane processing plants, which is rich in $\mathrm{P}, \mathrm{S}, \mathrm{Fe}, \mathrm{Mn}, \mathrm{Zn}$ and $\mathrm{Cu}$ and low in $\mathrm{N}$ is an ideal substrate for a biofertilizer plant. Thus, the potential of using Azotobacter spp. as a biological agent to produce fertilizer from sugarcane spent-wash is currently being looked at globally (Dawood et al., 2005; Patil et al., 2013). The spent-wash from sugarcane processing

\footnotetext{
Department of Agricultural Biology, Faculty of Agriculture, University of Peradeniya, Sri Lanka

2 Department of Crop Science, Faculty of Agriculture, University of Peradeniya, Sri Lanka

* Corresponding Author: venurah@pdn.ac.lk
} 
plants, which otherwise considered as a polutant can be used as a culture medium for the production of bio-fertilizer. For such task, mass culturing of initial inoculum will be an utmost necessity.

A higher yield of the initial inoculum will improve the efficiency of production in terms of yield and time. For culturing Azotobacter spp. bacterial broths including nitrogen-free liquid glucose medium (Lipman, 1904), Burk's medium (Wilson \& Knight, 1952), Azotobacter agar modified II (Atlas, 2010) and tryptic soy broth (TSB; as used by Aquilanti et al., 2004) are used in laboratories. It is noted that the protein enriched broth cultures generally result in higher bacterial growth compared to conventional media without an added protein source (Kihara \& Snell, 1960). However, the major constraint of using a protein enriched broth is the added cost of the protein supplement.

This study is aimed to compare the growth of Azotobacter spp. in culture media with or without an added protein source. Nevertheless, if there is a significant growth advantage, the added cost may give a better return in terms of time-efficiency and inoculum yield in biofertilizer production.

\section{METHODOLOGY}

\section{Preparation and inoculation of broth media}

To compare the growth performance of the Azotobacter spp. between the two inoculation media, A. chroococcum and A. vinelandii, two common Azotobacter spp. associated with sugarcane rhizosphere were selected. The two broths, tryptic peptone broth (TPB) and liquid glucose broth (LGB) were selected for the study as media with and without a protein supplement, respectively. From a pure culture of $A$. chroococcum and $A$. vinelandii $100 \mu \mathrm{l}$ were streaked on a modified liquid glucose agar medium [described by Lipman (1904) with the modifications made by Turner \& Gibson (1980)]. The petri dishes were incubated at $30{ }^{\circ} \mathrm{C}$ for three days and a loop-full of bacteria from a single colony forming unit (CFU) was inoculated into a $150 \mathrm{ml}$ Pyrex ${ }^{\circledR}$ conical flask containing $30 \mathrm{ml}$ of TPB [composition of 1 liter of TPB: enzymatic digest of casein (Pancreatic digest of casein) $17.0 \mathrm{~g}$, peptone bacteriological $3.0 \mathrm{~g}, \mathrm{NaCl} 5.0 \mathrm{~g}, \mathrm{~K}_{2} \mathrm{HPO}_{4} 2.5 \mathrm{~g}$ and dextrose (anhydrous) $2.5 \mathrm{~g}$ ] modified from Aquilanti et al. (2004).

The inoculated broth was incubated at $30{ }^{\circ} \mathrm{C}$ for 15 hours. From a well-mixed cultured broth, $100 \mu \mathrm{l}$ was used to make a ten-fold dilution series and $100 \mu \mathrm{l}$ of the diluted samples was inoculated into a modified liquid glucose agar medium using sterilized beads to obtain even distribution of the inoculum on the plate. After two days of incubation colony counts were made and CFU in the initial inoculum was calculated. From the broth cultures of two Azotobacter species in TPB, $1.5 \mathrm{ml}$ (which contained approximately $6.6 \times 10^{8} \mathrm{CFU}$ ) was inoculated separately into $150 \mathrm{ml}$ of freshly prepared TPB and LGB in $250 \mathrm{ml}$ Pyrex ${ }^{\circledR}$ conical flasks in ten replicates for each species [Composition of LGB: $\mathrm{K}_{2} \mathrm{HPO}_{4} 0.29 \mathrm{mM}, \mathrm{KH}_{2} \mathrm{PO}_{4} 1.1 \mathrm{mM}, \mathrm{CaCl}_{2} .2 \mathrm{H}_{2} \mathrm{O} 0.137 \mathrm{mM}$, $\mathrm{MgSO}_{4} \cdot 7 \mathrm{H}_{2} \mathrm{O} 0.811 \mathrm{mM}, \mathrm{Na}_{2} \mathrm{MoO}_{4} \cdot 2 \mathrm{H}_{2} \mathrm{O}$ trace, $\mathrm{Na}_{2} \mathrm{MoO}_{4}$ trace, $\mathrm{FeCl}_{3} \cdot 6 \mathrm{H}_{2} \mathrm{O}$ trace and Sucrose $58.4 \mathrm{mM}, \mathrm{pH}$ of the medium adjusted to 7 (Atlas, 2010)]. The broth cultures were incubated at $30^{\circ} \mathrm{C}$. After three hour incubation period the optical density (OD) of 
sub-samples drawn from the broth cultures were measured using a spectrophotometer (Model: Optizen POP, Mecasys Co. Ltd., Korea) at $620 \mathrm{~nm}$ wavelength. For each sample, three repeated OD measurements were taken. The measurements were repeated every 90 minutes until the OD values of the broth cultures started to drop. Un-inoculated TPB and LGB samples were used as the blank samples in OD measurements.

\section{Data analysis}

The significance of the broth type for the growth of Azotobactor species (OD values) was statistically analyzed using analysis of variance (ANOVA). Species, broth types, and species $\times$ broth type interaction were used as the main effects in ANOVA. As the species $\times$ broth type interaction was significant, regression analysis was performed for each species under each broth type separately. A non-linear regression with a second order polynomial (Delignette-Muller, 1998) was performed to explain the variability of OD values with time (i.e. with the highest $\mathrm{R}^{2}$ ). Data were analyzed using Statistical Analysis System (SAS) v9.13 (SAS Institute Inc, USA) and the interpretations were made at $P<0.05$. A cost analysis was done for the preparation of $1 \mathrm{~L}$ of TPB and LGB based on the ingredients used. The prices were based on Fisher Scientific International Inc. USA as of $19^{\text {th }}$ October, 2015.

\section{RESULTS AND DISCUSSION}

For a cost-effective production of bio-fertilizer an inoculation medium that facilitates rapid growth of Azotobacter spp. is essential. However, to our knowledge growth performance comparison of Azotobacter spp. in different media has not been reported todate. Thus, here we report the evaluation of the growth performance of two commonly used broth media, LGB and TPB, suitable for culturing Azotobacter spp. as an inoculum for biofertilizer production.

The standard TSB medium, which is commonly used to culture Azotobacter spp., consists of enzymatic digest of soybean meal and enzymatic digest of casein as sources of nitrogen. In the modified TPB medium used in the present study, nitrogen is supplied via peptone (peptone and tryptophan from animal tissue digest (Oxoid Ltd., Thermo Fisher Scientific Inc., UK)) and enzymatic digest of casein (pancreatic digest of casein by Sigma-Aldrich Co., USA). The OD value directly relates to the turbidity of the medium, which is a resultant of the cell density in the broth. Turbidity of the medium increased with time irrespective of the culture medium (Fig. 1). Throughout the experiment growth rates of the two Azotobacter species in TPB were higher compared to that in LGB (Fig. $2 \mathrm{~A}$ and $2 \mathrm{~B}$ ). The maximum growth of $A$. vinelandii and $A$. chroococcum were observed at 9 and 13.5 hours, respectively, after inoculation in TPB medium and continued to drop thereafter. However, in the LGB neither species reached the peak during the experimental period of 15 hours (Fig. 2 A and 2B). The observed growth patterns in the present study are in agreement with the sigmoidal growth curves for microorganisms reported in Monod (1949). 
The OD values were affected by species, broth type and species $\times$ broth type interaction (Table 1). Thus, the yield of Azotobacter inoculum varied significantly with the different species and the broth type used $(p<0.05)$.

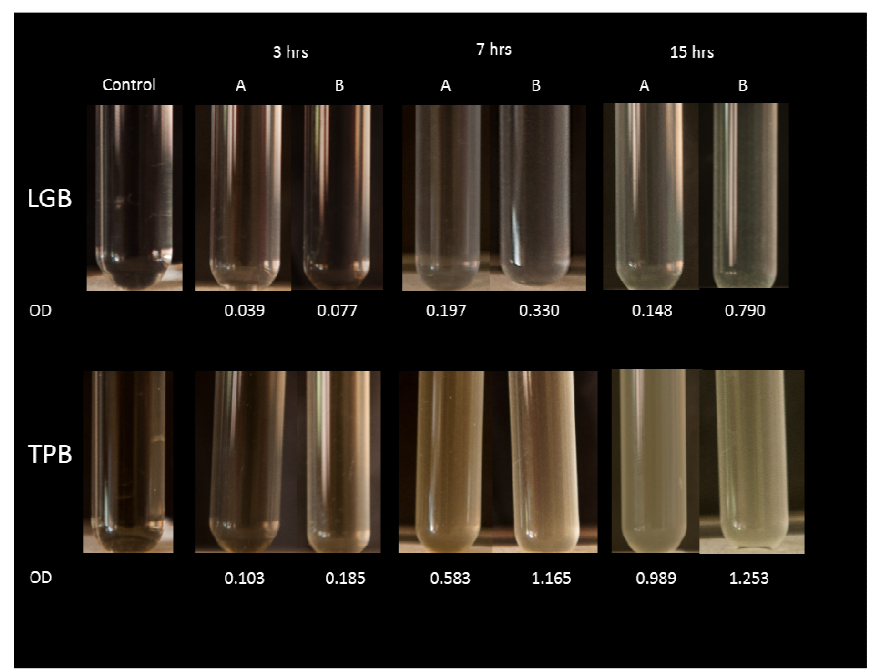

Fig. 1. Comparison of media turbidity and optical density (OD) measurements over 3, 7 and 15 hours after inoculation in liquid glucose broth (LGB) and tryptic peptone broth (TPB) for (A) A. vinelandii and (B) A. chroococcum

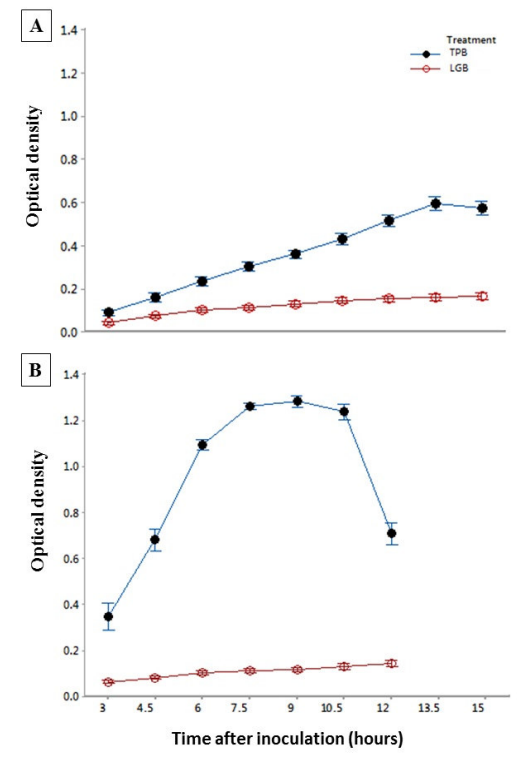

Fig. 2. Variation in optical density of (A) Azotobacter vinelandii and (B) Azotobacter chroococcum when grown in liquid glucose broth (LGB - open symbol) or tryptic peptone broth (TPB - close symbol) with time, mean \pm s.e., $\mathbf{n}=\mathbf{1 0}$ 
Table 1. The F-statistics and probability values of ANOVA test of optical density values observed for two different Azotobactor species cultured in two growth media $(p<0.05)$

\begin{tabular}{llll}
\hline Source & Df & F value & P \\
\hline Species & 1 & 553.65 & $<0.001$ \\
Broth type & 1 & 1954.80 & $<0.001$ \\
Species $\times$ Broth type & 1 & 596.16 & $<0.001$ \\
\hline
\end{tabular}

Changes in OD values with time could be best explained by a second order polynomial function for each species and broth type separately. The model equation is as follow (Eq1).

$$
\begin{aligned}
\mathrm{OD}=\mathrm{m} & +\left(\mathrm{C}_{1} \times \text { time }\right)+\left(\mathrm{C}_{2} \times \mathrm{time}^{2}\right) \text {------(Eq1) } \\
& \text { in which, } m, C_{1} \text { and } C_{2} \text { are model constants. }
\end{aligned}
$$

Coefficient of determination values ranged from $76-95 \%$ for the selected second order polynomial regression models (Table 2) indicating that a major proportion of the variability in OD values could be explained by the selected models using time as an independent variable. As indicted by model constant ' $\mathrm{m}$ ', which is the intercept, the OD values in the TPB were higher compared to that in LGB even at three hours after inoculation irrespective of the Azotobacter spp. (Table 2). During the log phase of the growth curve, the OD values of the TPB increased at a rate of 0.19 OD increment per hour than that of LGB. Cell mass production depends on protein availability of the medium (Kihara \& Snell, 1960). The reason for the slow growth rate of the Azotobacter spp. growing in the LGB could be the need to fix atmospheric $\mathrm{N}$ for catering own $\mathrm{N}$ demand in a $\mathrm{N}$ limiting medium, compared to TPB where nitrogen is supplied as peptone, tryptophan and casein proteins.

Table 2. The coefficient of determination $\left(R^{2}\right)$, coefficient of variance $(C V)$, mean optical density (OD) and the probability values (P) of the second order

\begin{tabular}{|c|c|c|c|c|c|c|c|}
\hline \multicolumn{2}{|l|}{ Factors } & \multirow{2}{*}{$\mathrm{R}^{2}$} & \multirow[b]{2}{*}{$\mathrm{CV}$} & \multirow{2}{*}{$\begin{array}{l}\text { OD } \\
\text { mean }\end{array}$} & \multicolumn{3}{|c|}{ Model constants } \\
\hline $\begin{array}{l}\text { Azotobacter } \\
\text { spp. }\end{array}$ & $\begin{array}{l}\text { Broth } \\
\text { type * }\end{array}$ & & & & $\mathrm{m}$ & $\mathrm{C} 1$ & $\mathrm{C} 2$ \\
\hline \multirow{2}{*}{ A. vinelandii } & LGB & 0.85 & 14.1 & 0.119 & -0.0205 & 0.0240 & -0.0008 \\
\hline & ТРВ & 0.95 & 10.9 & 0.361 & -0.0909 & 0.0599 & -0.0009 \\
\hline \multirow[t]{2}{*}{ A. chroococcum } & LGB & 0.76 & 12.8 & 0.109 & +0.0247 & 0.0154 & -0.0005 \\
\hline & ТPB & 0.93 & 9.4 & 0.946 & -1.2083 & 0.6053 & +0.0366 \\
\hline
\end{tabular}
polynomial regression. The probability of the model fit is $<0.001$.

*LGB - liquid glucose broth; TBP - tryptic peptone broth

Even though the species effect on the variation in OD values was significant irrespective of the broth type $(p<0.05)$, the species A. chroococcum showed a higher growth performance compared to $A$. vinelandii (Fig. $2 \mathrm{~A}$ and $2 \mathrm{~B}$ ). It is possible that $A$. 
chroococcum might have vigorous growth capability and better nutrient assimilation ability compared to $A$. vinelandii.

The cost of ingredients per liter of LGB and TPB were USD 2.25 and 5.12, respectively [based on the prices listed in Thermo Fisher Scientific Inc., USA (https://www.fishersci.com/us/en/home.html) retrieved on the 19/05/2015; prices less than US $\$ 0.01$ were rounded to US $\$ 0.01$ ]. Use of a protein supplemented medium is $127 \%$ expensive but there is a significant advantage with respect to harvest. Further, within 9 hrs of incubation, an OD value of 1.28 can be achieved in TPB, while it remained at 0.12 in LGB. Therefore, rapid bacterial yield can be achieved in the proteinsupplemented media. Even though the TPB is costly, considering the time and yield advantage, the use of a protein supplemented medium can still be considered as a feasible option for production of inoculum. To reduce the cost, we suggest to extend investigations on the use of non-purified, cost effective alternative protein sources such as crude soybean extracts in biofertilizer industry applications.

\section{CONCLUSIONS}

In the TPB Azotobacter spp. showed a better growth performance than in the LGB. Thus, a growth medium supplying N such as TPB is ideal for preparing Azotobactor inoculum. Considering the differences in magnitude of response by $A$. chroococcum and $A$. vinelandii to TPB, it is recommended to test the response of the inoculum to selected growth medium and optimize growth conditions before using the medium in biofertilizer production.

\section{ACKNOWLEDGEMENTS}

The authors wish to acknowledge Dr. H.A.M. Wickramasinghe for her valuable insight.

\section{REFERENCES}

Aquilanti, L., Favilli, F. and Clementi, F. (2004). Comparison of different strategies for isolation and preliminary identification of Azotobacter from soil samples. Soil Biol. Biochem. 36, 1475 - 1483.

Atlas, R.M. (2010). Handbook of Microbiological Media. $4^{\text {th }}$ Edition, Tylor \& Francis group, USA.

Dawood, M.S., Bose, M.S.C. and Nadu, T. (2005). Effect of integrated use of distillery effluent and fertilisers on soil properties and yield of sugarcane in sandy loam soil. Notes. 92(June), 349 - 354.

Kihara, H. and Snell, E.E. (1960). Peptides and bacterial growth VIII. The nature of strepogenin. J. Biol. Chem. 235, 1409 - 1414. 
Kizilkaya, R. (2008). Yield response and nitrogen concentrations of spring wheat (Triticum aestivum) inoculated with Azotobacter chroococcum strains. Ecological Engineering. 33(2), 150 - 156.

Lipman, J.G. (1904). Soil bacteriological studies. Further contributions to the physiology and morphology of the members of the Azotobacter group. Report of the New Jersey State Agricultural Experiment Station. 237 - 289.

Monod, J. (1949). The growth of bacterial cultures. Annu. Rev. Microbiol. 3(1), 371 394.

Patil, N.N., Jadhav, S., Ghorpade, S. S. and Sharma, A. B. (2013). Isolation and enrichment of sugar press mud (SPM) adapted microorganism for production of biofertilizer by using sugar press mud. Int. J. Adv. Biotechnol. Res. 4(1), $96-104$.

Singh, J.S., Pandey, V.C. and Singh, D.P. (2011). Efficient soil microorganisms: A new dimension for sustainable agriculture and environmental development. Agricult. Ecosys. Environ. 140(3-4), 339 - 353.

Tejera, N., Lluch, M., Martínez-Toledo, M. V. and González-López, J. (2005). Isolation and characterization of Azotobacter and Azospirillum strains from the sugarcane rhizosphere. Plant Soil. 270(1), 223 - 232.

Turner, G.L. and Gibson, A.H. (1980). Measurement of nitrogen fixation by indirect means. In F. Bergersen, ed. Methods for Evaluating Biological Nitrogen Fixation 111138. John Wiley \& Son, USA.

Wilson, P.W. and Knight, S.G. (1952). Experiments in Bacterial Physiology, Burgess Publishing Co, USA.

Yasari, E. and Patwardhan, A.M. (2007). Effects of (Azotobacter and Azosperillum) inoculants and chemical fertilizers on growth and productivity of canola (Brassica napus L.). Asian J. Plant Sci. 6(1),77 - 82. 